\title{
A Unified Moisture Mode Framework for Seasonality of the Madden-Julian Oscillation
}

\author{
XIANAN JIANG \\ Joint Institute for Regional Earth System Science and Engineering, University of California, Los Angeles, Los \\ Angeles, and Jet Propulsion Laboratory, California Institute of Technology, Pasadena, California \\ ÁNGel F. AdAMES AND Ming ZHAO \\ NOAA/Geophysical Fluid Dynamics Laboratory, Princeton, New Jersey \\ DUANE WALISER \\ Jet Propulsion Laboratory, California Institute of Technology, Pasadena, California \\ ERIC MALONEY \\ Department of Atmospheric Science, Colorado State University, Fort Collins, Colorado
}

(Manuscript received 6 October 2017, in final form 20 February 2018)

\begin{abstract}
The Madden-Julian oscillation (MJO) exhibits pronounced seasonality. While it is largely characterized by equatorially eastward propagation during the boreal winter, MJO convection undergoes marked poleward movement over the Asian monsoon region during summer, producing a significant modulation of monsoon rainfall. In classical MJO theories that seek to interpret the distinct seasonality in MJO propagation features, the role of equatorial wave dynamics has been emphasized for its eastward propagation, whereas coupling between MJO convection and the mean monsoon flow is considered essential for its northward propagation. In this study, a unified physical framework based on the moisture mode theory, is offered to explain the seasonality in MJO propagation. Moistening and drying caused by horizontal advection of the lower-tropospheric mean moisture by MJO winds, which was recently found to be critical for the eastward propagation of the winter MJO, is also shown to play a dominant role in operating the northward propagation of the summer MJO. The seasonal variations in the mean moisture pattern largely shape the distinct MJO propagation in different seasons. The critical role of the seasonally varying climatological distribution of moisture for the MJO propagation is further supported by the close association between model skill in representing the MJO propagation and skill at producing the lower-tropospheric mean moisture pattern. This study thus pinpoints an important direction for climate model development for improved MJO representation during all seasons.
\end{abstract}

\section{Introduction}

One of the most prominent modes of variability in the earth's atmosphere, the Madden-Julian oscillation (MJO), remains poorly represented in present-day climate and weather forecast models (Neena et al. 2014; Jiang et al. 2015; Neena et al. 2017; Ahn et al. 2017), greatly limiting our capability to conduct short-term climate prediction of extreme weather activity. The grand challenge in modeling the MJO is largely due to

Corresponding author: Dr. Xianan Jiang, xianan@ucla.edu our limited understanding of essential processes regulating this important form of variability.

The MJO exhibits pronounced seasonality in its propagation characteristics. During boreal winter, the MJO is characterized by the equatorial eastward propagation (Madden and Julian 1994). In contrast, it exhibits marked poleward movement over the Indian Ocean (IO) and western Pacific (WP) during summer with a relatively weak eastward-propagating component (e.g., Lau and Chan 1986; Hsu and Weng 2001; Jiang et al. 2004). Various theories have been proposed to explain the distinct seasonality in MJO propagation (e.g., Waliser 2006; Wang 2012). One traditional view of the eastward 
propagation of the winter MJO maintains through triggering of new convection to the east by frictional moisture convergence in the planetary boundary layer (PBL) associated with the equatorial Kelvin wave response to the MJO convective heating (e.g., Salby et al. 1994; Wang and Li 1994; Maloney and Hartmann 1998). Meanwhile, past work has suggested that northward propagation of the summer MJO can be supported by preconditioning of new convection to the north associated with PBL convergence induced by barotropic cyclonic vorticity anomalies caused by coupling between the MJO convection and summer mean flow (e.g., Jiang et al. 2004). Based on a theoretical framework and considering the MJO as a convectively Kelvin-Rossby wave couplet, Li (2014) hypothesized that the northward shift of convergence zone and maximum moisture away from the equator in boreal summer over the Indian monsoon region tends to damp the equatorial moist Kelvin waves, while destabilizing the Rossby waves, thus leading to meridional bifurcation of the MJO convection off Sumatra.

Most recently, the concept of a "moisture mode" (Raymond and Fuchs 2009; Sobel and Maloney 2012, 2013; Adames and Kim 2016) has been widely employed to understand maintenance and propagation mechanisms for the MJO, with a particular focus on the eastward propagation of winter MJO. One of the most important findings is that the advection of column-integrated moist static energy (MSE) or equivalently the lowertropospheric moisture, particularly its horizontal component, plays a critical role in driving the eastward propagation of the winter MJO (e.g., Maloney 2009; Andersen and Kuang 2012; Hsu and Li 2012; Cai et al. 2013; Chikira 2014; Kim et al. 2014; Pritchard and Bretherton 2014; Adames and Wallace 2015; Benedict et al. 2015; Jiang 2017; Kim et al. 2017), although a role of vertical advection was also noted (e.g., Hsu and Li 2012; Sobel et al. 2014; Yokoi and Sobel 2015; Wang et al. 2017). For the horizontal advection, the winter mean low-level moisture pattern, characterized by an equatorial maximum between $140^{\circ}$ and $150^{\circ} \mathrm{E}$ with strong westward and poleward gradients over the Indo-Pacific region (Fig. 1a), holds the key for the MJO eastward propagation. Given an active MJO convection over the IO, both zonal and meridional advection of mean moisture by MJO winds lead to moistening (drying) to the east (west) of MJO convection, driving its eastward propagation. The critical role of the mean moisture pattern for eastward winter MJO propagation has been recently confirmed by multimodel climate simulations (Jiang 2017; Gonzalez and Jiang 2017) and hindcasts (Kim 2017).

While moisture mode theory has been mainly employed for the winter MJO, a recent diagnostic study on MJO moisture budget by Adames et al. (2016) suggests that distinct MJO propagation between winter and summer is associated with seasonal variations in the mean moisture pattern (Fig. 1). In this study, by conducting a detailed moisture entropy budget analysis for the northward propagation of the summer MJO over the IO, we illustrate that horizontal advection of seasonal mean moisture by MJO winds is also critical for the northward propagation of the boreal summer MJO, similar to its role in eastward boreal winter MJO propagation. These results thus provide a unified physical interpretation for both the eastward and northward propagation of the MJO.

\section{Dataset}

While MSE budget processes associated with the winter MJO have been comprehensively investigated, analyses in this study mainly focus on the northward propagation of the summer MJO over the IO from May to October during 1998-2012. Primary observational datasets used in this study include the 3-hourly Tropical Rainfall Measuring Mission (TRMM) rainfall (3B42v7 data; Huffman et al. 2007) at $0.25^{\circ}$ spatial resolution, and daily $3 \mathrm{D}$ temperature, specific humidity, and winds from the ECMWF interim reanalysis (ERA-Interim; Dee et al. 2011) with a horizontal resolution of $1.5^{\circ} \times 1.5^{\circ}$. Daily TRMM-based 3D radiative heating (L'Ecuyer and McGarragh 2010; Jiang et al. 2011) and surface heat fluxes from the objectively analyzed air-sea fluxes (OAFlux) project (Yu et al. 2008) are also used to examine impacts of radiation and surface fluxes on MJO propagation.

Daily output of rainfall and specific humidity from 20-yr simulations of 24 GCMs, participating in the MJO Task Force (MJOTF)/GEWEX Atmospheric System Study (GASS) MJO model intercomparison project (Petch et al. 2011; Jiang et al. 2015; Klingaman et al. 2015) is also analyzed to examine the role of the mean moisture pattern for northward propagation of the summer MJO. Details of the GCMs analyzed in this study can be found in Jiang et al. (2016). For the following analyses, all observed and model fields are interpolated onto the same standard $2.5^{\circ} \times 2.5^{\circ}$ horizontal grids and 22 vertical pressure levels.

\section{Results}

\section{a. Moist entropy analysis for northward MJO propagation}

While the moist entropy is largely equivalent to the MSE, the conservation of the MSE depends on the hydrostatic approximation, which is not precisely valid for a moving parcel; in contrast, the moist entropy is conserved by definition in slow, moist, and dry adiabatic 


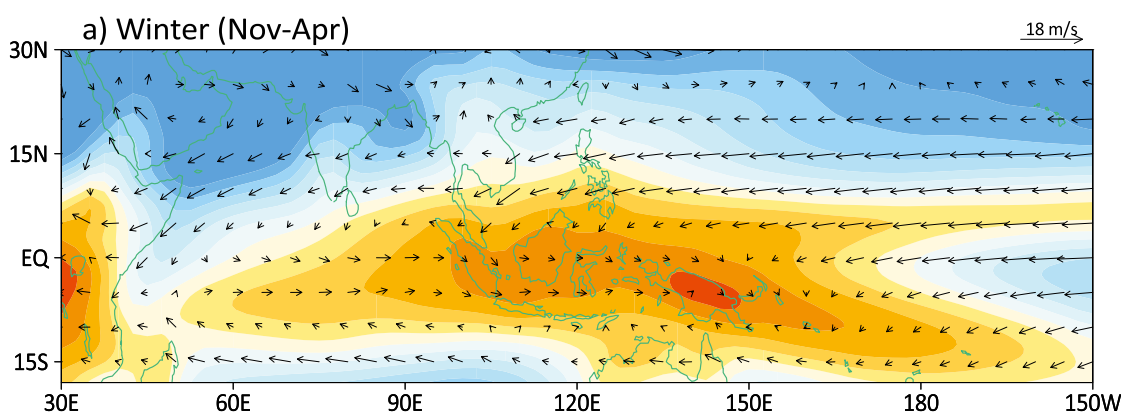

b) Summer (May-Oct)
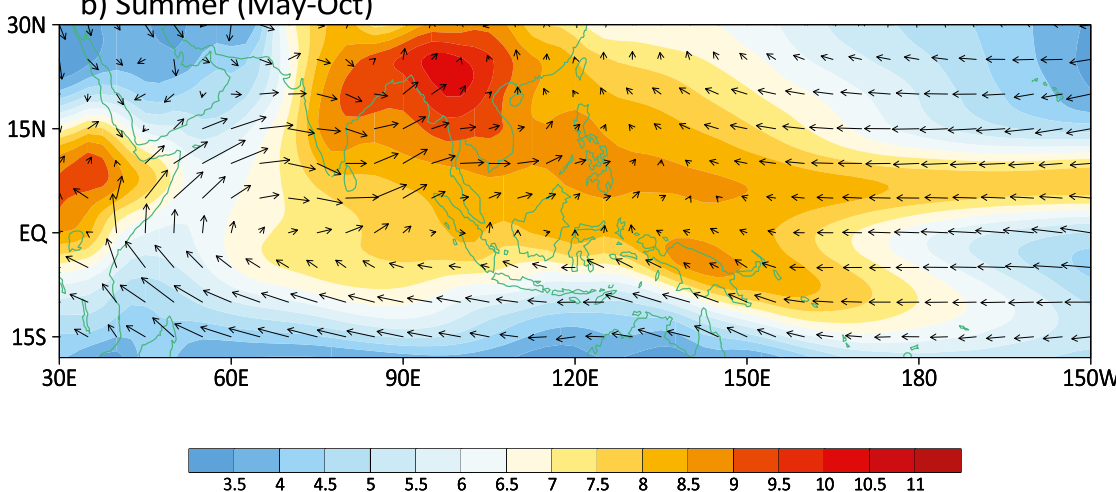

FIG. 1. (a) Winter (November-April) and (b) summer (May-October) mean lowertropospheric $\left(900-600 \mathrm{hPa}\right.$ ) specific humidity (shaded; $\mathrm{g} \mathrm{kg}^{-1}$ ), and mean 850-hPa winds [vectors; see a scale at the top right of (a)] based on ERA-Interim from 1998 to 2012.

processes (Madden and Robitaille 1970; Raymond et al. 2009; Raymond 2013). Therefore, similarly to previous MSE analyses for the winter MJO (Benedict et al. 2014; Jiang 2017), the moist entropy (ME or $S$ ) is used in this study as an alternate form of the conventional MSE following Raymond et al. (2009), which is defined as

$$
\begin{aligned}
S= & T_{R}\left(C_{\mathrm{PD}}+r_{V} C_{\mathrm{PV}}\right) \ln \left(\frac{T}{T_{R}}\right)-R_{D} T_{R} \ln \left(\frac{p_{D}}{p_{R}}\right) \\
& -r_{V} R_{V} T_{R} \ln \left(\frac{p_{V}}{e_{\mathrm{SF}}}\right)+L_{V} r_{V},
\end{aligned}
$$

where $C_{\mathrm{PD}}, R_{D}$, and $p_{D}$ are the specific heat, gas constant, and partial pressure of dry air respectively; $C_{\mathrm{PV}}$, $R_{V}$, and $p_{V}$ are the specific heat, gas constant, and partial pressure of water vapor, respectively; $r_{V}$ is the water vapor mixing ratio; $T$ is air temperature; $T_{R}$ is the reference temperature of $273.15 \mathrm{~K} ; p_{R}$ is the reference pressure $(1000 \mathrm{hPa})$ for dry air; $e_{\mathrm{SF}}=611 \mathrm{~Pa}$; and $L_{V}=$ $2.5 \times 10^{6} \mathrm{~J} \mathrm{~kg}^{-1}$ is the enthalpy of vaporization.

The vertically integrated ME equation can then be written as

$$
\left[\frac{\partial S}{\partial t}\right]=-[\mathbf{v} \cdot \nabla S]-\left[\omega\left(\frac{\partial S}{\partial p}\right)\right]+F_{s}+Q_{R},
$$

where the square brackets represent mass-weighted vertical integrals from 1000 to $100 \mathrm{hPa}, \mathbf{v}$ is the horizontal wind, $\omega$ is the vertical pressure velocity, $F_{s}$ is total surface fluxes (including latent and sensible heat fluxes), and $Q_{R}$ is vertically integrated radiative heat fluxes (including longwave and shortwave heat fluxes).

A brief validation of coherence between rainfall and ME anomalies associated with northward propagation of the MJO is first provided. The northward propagation of the summer MJO with a phase speed of about $1^{\circ}$ lat day ${ }^{-1}$ is clearly evident over the IO sector $\left(75^{\circ}-90^{\circ} \mathrm{E}\right.$; Fig. $\left.2 \mathrm{a}\right)$ based on lag-regression of 20-100-day filtered rainfall against itself in an IO box $\left(2.5^{\circ}-7.5^{\circ} \mathrm{N}, 75^{\circ}-90^{\circ} \mathrm{E}\right.$; see box in Fig. $\left.2 \mathrm{c}\right) .^{1}$ Regressed vertically integrated ME anomalies exhibit similar propagation features, and are generally in phase with rainfall (Fig. 2b). Spatial patterns of regressed rainfall and $\mathrm{ME}$ anomalies at lag 0 day are further displayed in Figs. 2c, d. Positive (negative) MJO rainfall anomalies are generally collocated with positive (negative) ME anomalies, with both of which exhibiting a southeast-northwestward tilt. The consistency between rainfall and ME anomalies of the

\footnotetext{
${ }^{1}$ Considering the focus of this study on northward propagation of the boreal summer MJO, a box region centered at $5^{\circ} \mathrm{N}$ is applied for lag-regression calculations here.
} 

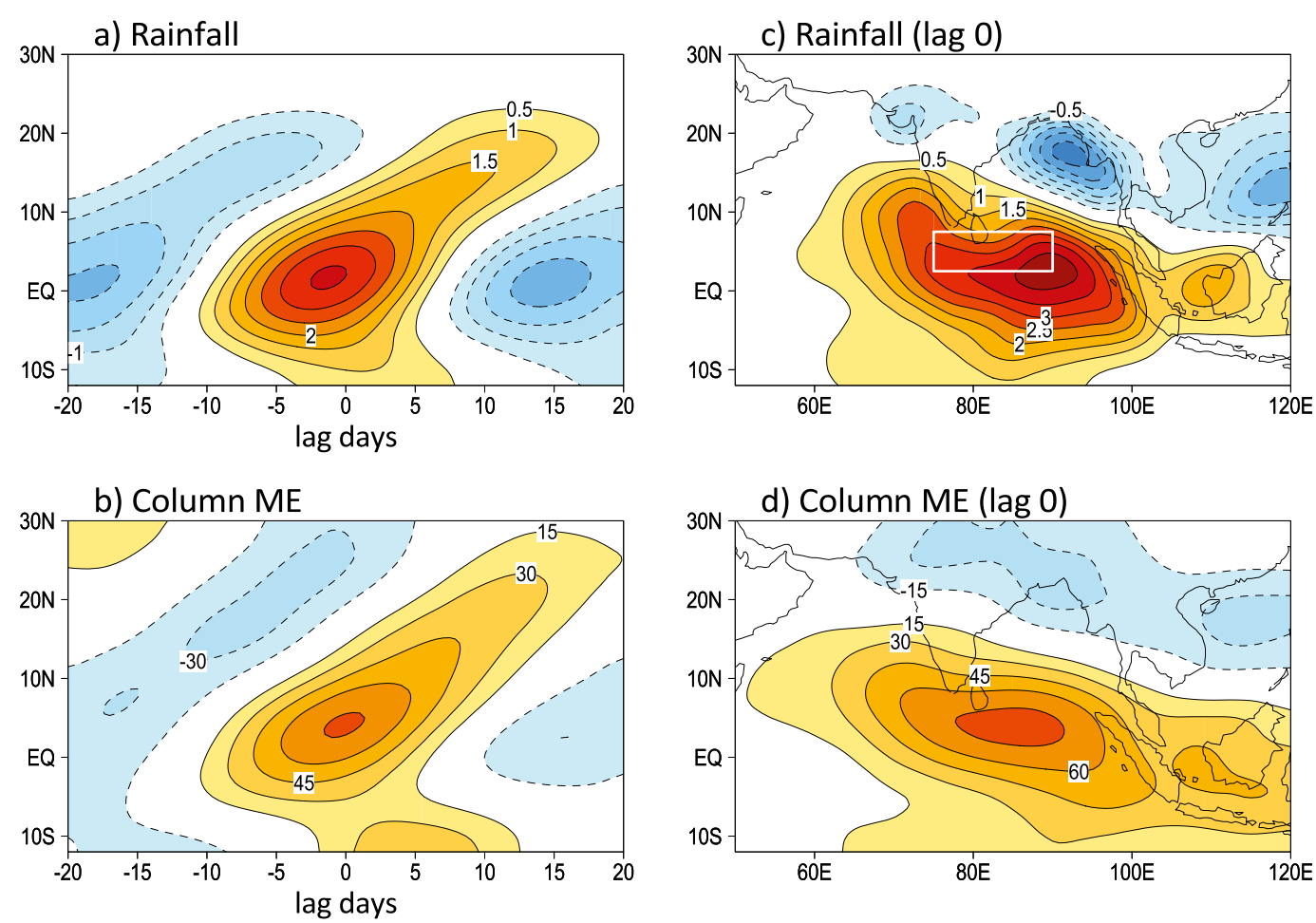

FIG. 2. Latitude-time evolution of the observed (a) rainfall $\left(\mathrm{mm} \mathrm{day}^{-1}\right)$ and (b) vertically integrated moisture entropy $\left(10^{5} \mathrm{~J} \mathrm{~m}^{-2}\right)$ anomalies averaged over the Indian Ocean sector $\left(75^{\circ}-90^{\circ} \mathrm{E}\right)$ associated with the summer MJO, derived by lag regressions of corresponding 20-100-day bandpass-filtered anomalies against 20-100-day rainfall anomalies in the Indian Ocean box $2.5^{\circ}-7.5^{\circ} \mathrm{N}, 75^{\circ}-90^{\circ} \mathrm{E}$ [shown in (c)]. Spatial regression patterns of (c) rainfall and (d) ME anomalies on lag 0 day.

summer MJO is thus in concert with the moisture mode theory, and justifies using the ME analysis for investigating the $\mathrm{MJO}$ northward propagation mechanism.

Figure 3 a illustrates the regressed anomalous columnintegrated $\mathrm{ME}$ tendency pattern at day 0. Positive (negative) ME tendency is evident to the north (south) of MJO convection and ME (Fig. 2), consistent with its northward propagation. The pattern of each ME budget term on the rhs of Eq. (2) (Figs. 3b-e) suggests that horizontal ME advection (Fig. 3b) is the main contributor to the total ME tendency in Fig. 3a, with strong positive horizontal advection over the Bay of Bengal (BoB) and near-coastal regions of the Arabian Sea being partially offset by the vertical advection, and negative horizontal advection near the equator being partially offset by radiative effects and surface fluxes. The positive vertical ME advection over the land area of the Indian subcontinent, associated with local anomalous MJO downward motion possibly caused by topographic influences of the Ghats over the western coast, partially contributes to the local total ME tendency, leading to a smooth positive ME tendency belt to the north of MJO from the Arabian Sea to BoB. ME tendencies resulting from $Q_{R}$ and $F_{s}$ are largely positive (negative) over the convectively active (inactive) region of the MJO, indicating that these two energy sources amplify the summer MJO, similar to the case of the winter MJO (e.g., Raymond 2001; Maloney and Sobel 2004; Andersen and Kuang 2012; Sobel et al. 2014; Kim et al. 2014; Arnold and Randall 2015; Yokoi and Sobel 2015; Jiang et al. 2016; Jiang 2017).

The relative importance of each ME term for northward MJO propagation is assessed by projecting its spatial pattern (Figs. 3b-e) onto the total ME tendency (Fig. 3a) over the domain of $5^{\circ} \mathrm{S}-25^{\circ} \mathrm{N}, 50^{\circ}-110^{\circ} \mathrm{E} .^{2}$ The dominant role of horizontal ME advection for the total ME tendency is clearly evident (Fig. 4a). While the vertical ME advection and radiative effects generally have a weak impact on propagation, surface fluxes tend to inhibit the northward propagation, largely because of the reduction of westerly mean monsoon winds by easterly MJO anomalous winds to the north of the MJO convection (e.g., cf. Figs. $1 \mathrm{~b}$ and $5 \mathrm{a}$ ). A positive ME budget residual is also noted (Fig. 4a), possibly resulting

\footnotetext{
${ }^{2}$ Results shown here are not sensitive to slight changes of projection domain.
} 

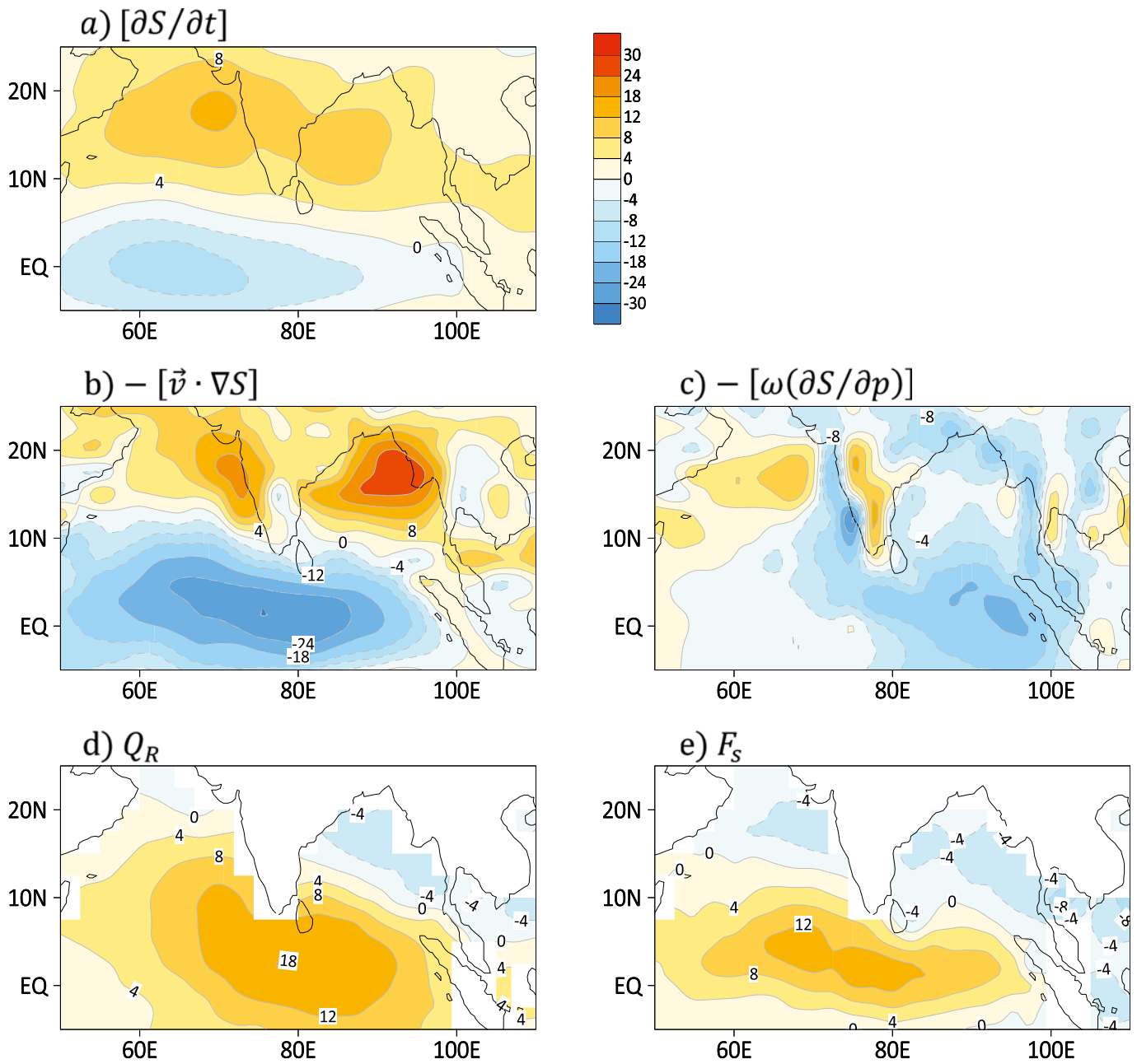

FIG. 3. Lag 0 day regressed patterns for (a) total vertically integrated ME tendency and its budget terms $\left(\mathrm{W} \mathrm{m}^{-2}\right)$, including (b) horizontal and (c) vertical ME advection, (d) radiative heating, and (e) surface fluxes in the observations. Note that TRMM-based $Q_{R}$ and $F_{s}$ from the OAFlux project are only available over ocean.

from spatial interpolation and the analysis increment in the reanalysis data (Kiranmayi and Maloney 2011; Mapes and Bacmeister 2012), and the use of satellitebased $Q_{R}$ and surface heat flux estimates.

To further identify specific processes associated with horizontal ME advection for northward MJO propagation, both horizontal winds and $\mathrm{ME}$ are decomposed into three different time scales: low-frequency ( $>100$ days, with mean annual cycle included), intraseasonal (20100 days; e.g., MJO), and high-frequency ( $<20$ days) time scales. The contribution of each horizontal ME advection component to the northward propagation is indicated by projections of its corresponding lag 0 day regressed patterns onto the total ME tendency (Fig. 4b). Clearly evident is that the background $\mathrm{ME}$ advection by MJO winds $\left[-\mathbf{v}^{\prime} \cdot \nabla S_{m}\right]$ plays a dominant role in the total horizontal ME advection and thus northward summer MJO propagation, the same term that largely controls eastward propagation of the winter MJO (e.g., Kim et al. 2014; Benedict et al. 2015; Adames and Wallace 2015; Jiang 2017; Kim et al. 2017). Further decomposition of the total $\left[-\mathbf{v}^{\prime} \cdot \nabla S_{m}\right]$ term into zonal and meridional components (Fig. 4b, right) suggests a dominant contribution by the zonal advection.

As vertically integrated $\mathrm{ME}$ variations are largely dominated by the low-level moisture, the above result slightly differs from that of Adames et al. (2016). Based on a moisture budget analysis for the summer MJO over a broad Indo-Pacific region between $30^{\circ} \mathrm{S}$ and $30^{\circ} \mathrm{N}$, Adames et al. (2016) suggested that in addition to [ $-\mathbf{v}^{\prime}$. $\left.\nabla S_{m}\right]$, advection of anomalous MJO moisture by the mean monsoon circulation $\left[-\mathbf{v}_{m} \cdot \nabla S^{\prime}\right]$ also plays a dominant role for propagation of the summer MJO. While this latter term contributes to total ME tendency in Fig. 3a over some regions [e.g., the moistening to the north of the MJO convection over the BoB as suggested 
a) Pattern projection of each budget term on total column ME tendency

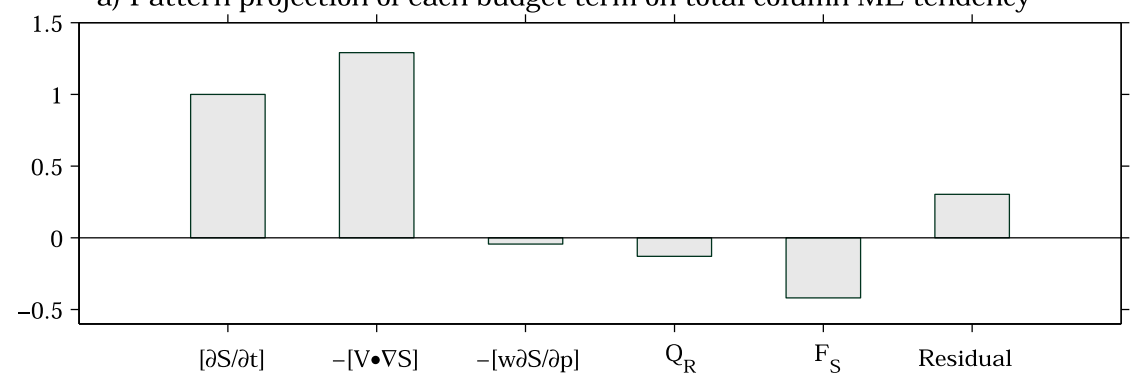

b) Decomposition of total ME horizontal advection

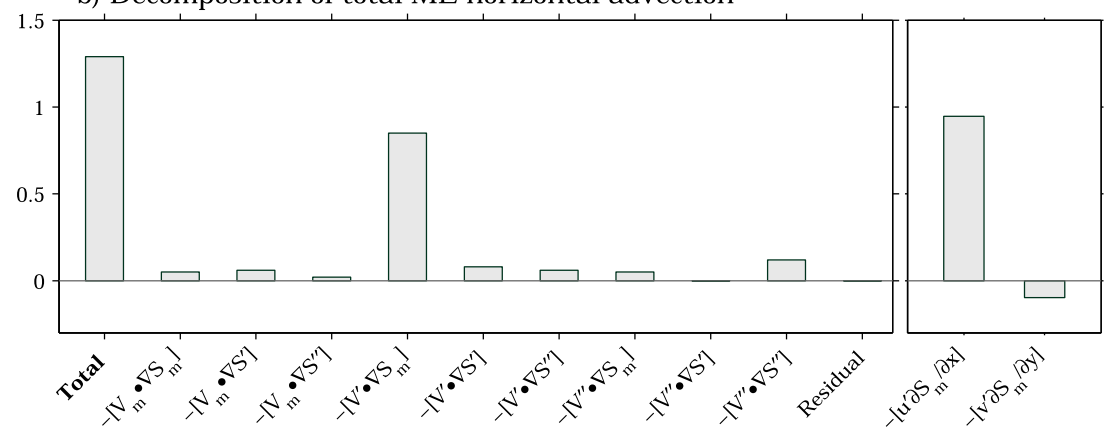

FIG. 4. (a) Relative role of each ME component for northward MJO propagation by projecting spatial pattern of each ME budget term over the IO $\left(5^{\circ} \mathrm{S}-25^{\circ} \mathrm{N}, 50^{\circ}-110^{\circ} \mathrm{E}\right)$ onto the total ME tendency pattern (Fig. 3a). (b), (left) Decomposition of the total horizontal ME advection by three different time scales: low-frequency variability with period greater than 100 days (denoted by subscript $m$ ), MJO time scale with a period between 20 and 100 days (denoted by a prime), and high-frequency variability (denoted by a double prime). (b), (right) Decomposition of $\left[-\mathbf{v}^{\prime} \cdot \nabla S_{m}\right]$ by zonal and meridional components.

in Adames et al. (2016)], its projection on total ME tendency pattern is rather weak in our study (Fig. 4b). We have verified that this difference is largely due to their compositing scheme and larger domain of study.

To demonstrate how advection of the mean ME or low-level moisture by the MJO circulation leads to northward MJO propagation, Fig. 5 presents 900-600hPa-averaged summer mean moisture (shaded) and MJO winds based on regression at day 0 . Associated with northwest-southeast-slanted MJO rainfall anomalies near the equator and suppressed MJO convection to the north of $10^{\circ} \mathrm{N}$ (Fig. 2c), the anomalous MJO circulation near the equator exhibits modified Gill-type responses with stronger amplitude to the north of the equator, partially resulting from influences of strong vertical easterly shear of summer monsoon circulation (Wang et al. 2003; Jiang and $\mathrm{Li}$ 2005). As a result, strong anomalous easterlies prevail between $10^{\circ}$ and $20^{\circ} \mathrm{N}$. Meanwhile, in stark contrast to the winter mean moisture pattern (also see Fig. 1), the maximum in the summer mean moisture is displaced over South Asia near $20^{\circ} \mathrm{N}$, with two local maxima between $10^{\circ}$ and $20^{\circ} \mathrm{N}$ : one over India and another over Indo-China. Therefore, advection of this mean moisture pattern by easterly MJO winds leads to moistening over BoB and west of the Ghats (e.g., Fig. 3b). Moreover, drying near the equator as a result of mean moisture advection by the

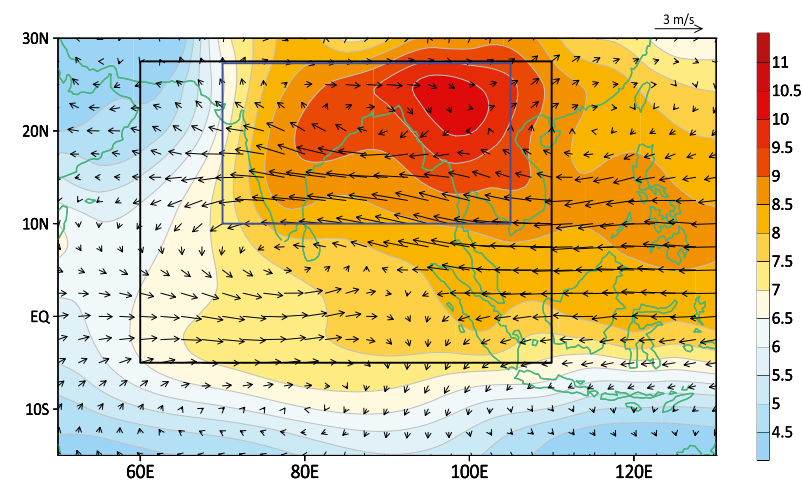

FIG. 5. Summer (May-October) mean 900-600-hPa-averaged specific humidity (shading; $\mathrm{g} \mathrm{kg}^{-1}$ ) and anomalous MJO winds derived by lag-0-day regression onto the 20-100-day filtered rainfall anomalies over the IO base point (vectors; see scale at the top right). The two rectangular boxes denote regions where summer mean lowlevel moisture pattern is highly correlated to MJO northward propagation based on multimodel simulations as discussed in section $3 \mathrm{~b}$. 

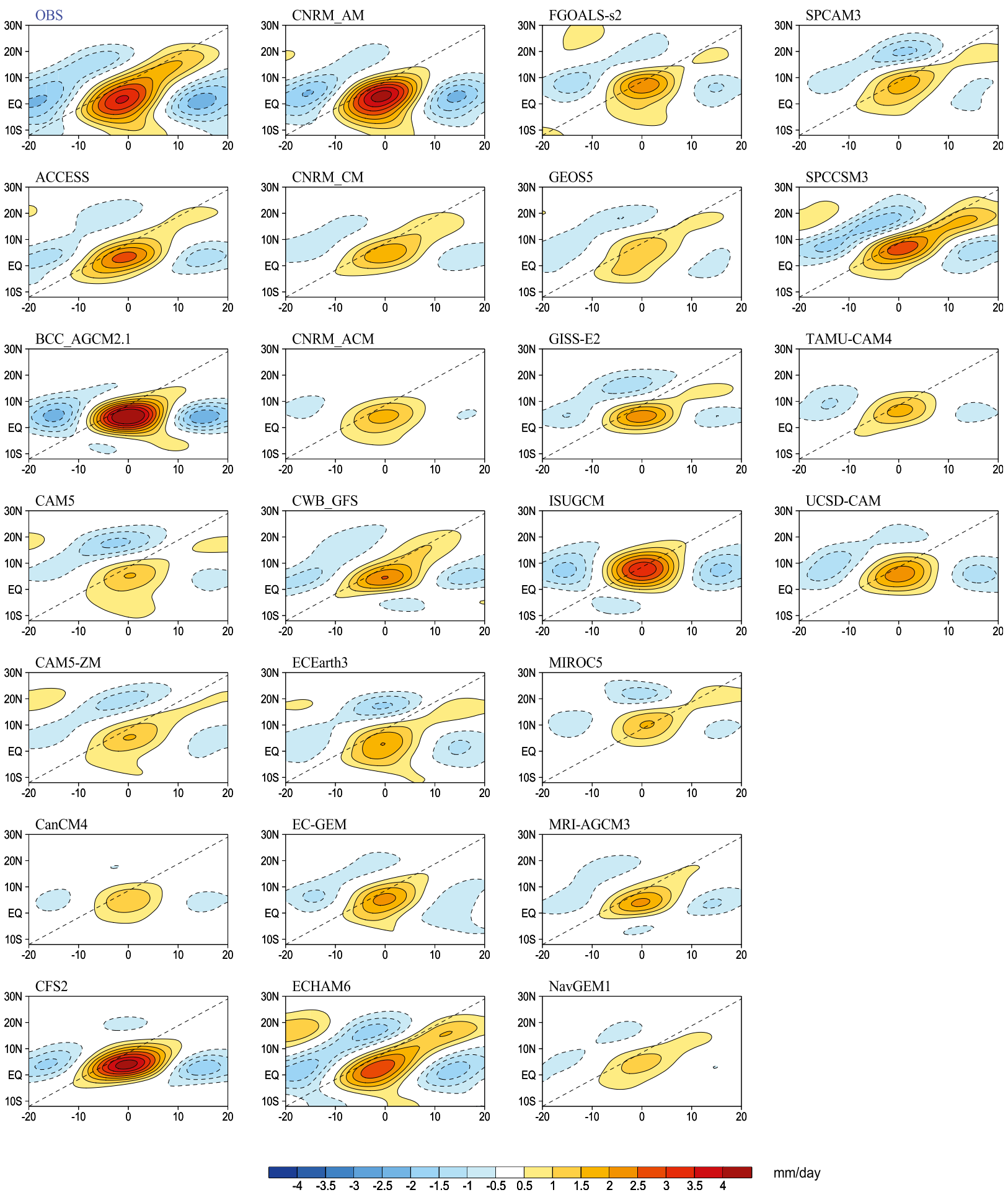

$\mathrm{mm} /$ day

FIG. 6. Latitude-time evolution of rainfall anomalies by lag-regression of 20-100-day bandpass-filtered anomalous rainfall against its averaged value over the IO $\left(2.5^{\circ}-7.5^{\circ} \mathrm{N}, 75^{\circ}-90^{\circ} \mathrm{E}\right)$ in observations and multimodel simulations from the MJOTF/GASS MJO model comparison project. Rainfall anomalies are averaged over $75^{\circ}-90^{\circ} \mathrm{E}$. Dashed lines in each panel denote the $1^{\circ}$ lat day ${ }^{-1}$ northward propagation phase speed. Note that the observed rainfall evolution shown in the top-left panel is duplicated from Fig. 2a. 
westerly anomalous MJO winds associated with the Rossby wave response to MJO convection leads to a meridional dipole ME tendency pattern that drives northward MJO propagation, a process largely similar to that described in Adames et al. (2016).

A previous study by Prasanna and Annamalai (2012) suggested that horizontal MSE advection is critical in initiating intraseasonal Indian monsoon breaks, which is in accord with results in this study although their study focused on the suppressed phase of the summer MJO. Moreover, results from this analysis are also consistent with diagnostic studies using remote-sensed observations that positive moisture advection tends to play an important role in triggering abrupt transitions from shallow cumulus to deep convections, thus provide preconditioning of deep convection associated with the summer MJO (Wong et al. 2011; Wang et al. 2015).

\section{b. Mean low-level moisture and the MJO northward propagation in multimodel simulations}

The analyses above thus suggest a critical role for the summer mean moisture pattern in northward MJO propagation. This is further supported by multimodel analysis based on $24 \mathrm{GCM}$ simulations from the MJOTF/GASS MJO model intercomparison project. As in Neena et al. (2017), model fidelity in representing northward propagation of the summer MJO is denoted by the pattern correlation of the simulated lag-regressed rainfall evolution pattern over the $\mathrm{IO}\left(75^{\circ}-90^{\circ} \mathrm{E}\right)$ against its observational counterpart. Figure 6 presents lagregressed rainfall evolution onto a base point over $2.5^{\circ}-7.5^{\circ} \mathrm{N}, 75^{\circ}-90^{\circ} \mathrm{E}$ in model simulations along with the observed counterpart (top-left panel; identical to Fig. 2a). As reported in details by Neena et al. (2017), many GCMs exhibit large deficiencies in representing northward propagation of the summer MJO. To obtain more reliable model skill for the MJO northward propagation, the lag-regressed $\mathrm{MJO}$ rainfall anomalies $\left(0^{\circ}-25^{\circ} \mathrm{N}\right.$; from -20 to 20 days $)$ in models and observations are also derived against other three different IO base points over $5^{\circ}$ latitude strips between $75^{\circ}$ and $90^{\circ} \mathrm{E}$ centered at $2.5^{\circ}, 7.5^{\circ}$, and $10^{\circ} \mathrm{N}$, respectively, in addition to that centered at $5^{\circ} \mathrm{N}$ as shown in Fig. 6 , and the final skill for the MJO northward propagation in a model is the average of the four pattern correlation scores.

Meanwhile, model fidelity in representing the summer mean low-level moisture pattern can be derived by the pattern correlation of simulated $900-600-\mathrm{hPa}$-averaged mean moisture pattern against the observed. Figure 7 presents a scatterplot between model skill for the MJO northward propagation and the summer mean low-level moisture pattern over a broad Indian monsoon domain $5^{\circ} \mathrm{S}-27.5^{\circ} \mathrm{N}, 60^{\circ}-110^{\circ} \mathrm{E}$ (black rectangle in Fig. 5) across

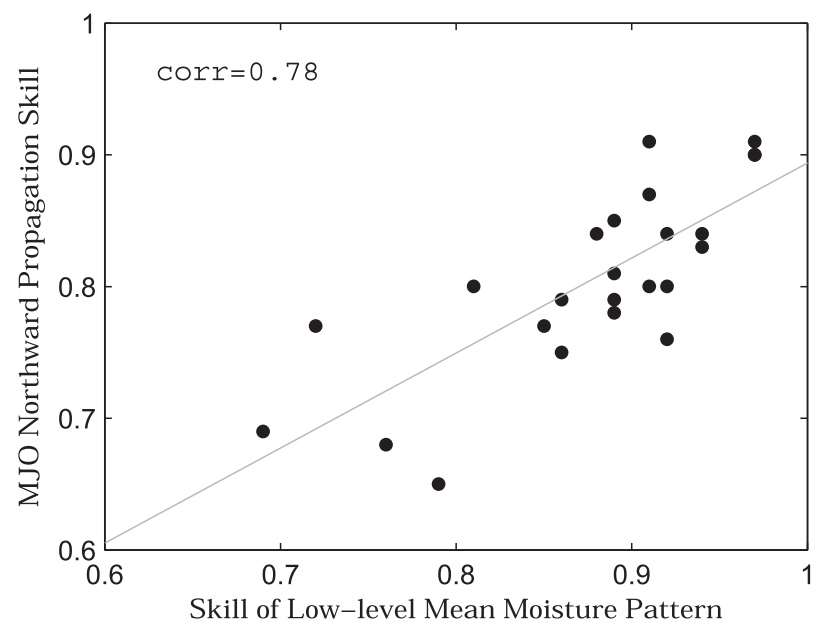

FIG. 7. Scatterplot between model skill for 900-600-hPaaveraged summer mean specific humidity pattern over the Indian monsoon region of $5^{\circ} \mathrm{S}-27.5^{\circ} \mathrm{N}, 60^{\circ}-110^{\circ} \mathrm{E}$ (see black rectangle in Fig. 5) and skill for northward MJO propagation based on multimodel simulations. A linear best-fit regression line by least squares means is shown by the gray line, and the correlation coefficient is shown in the top-left corner.

the multimodel simulations. A close association between the summer mean low-level moisture pattern over the Indian monsoon region and the northward MJO propagation is clearly evident with a high correlation of 0.78 (Fig. 7). An even higher correlation of 0.82 is noted between model skill of MJO northward propagation and skill in reproducing the summer mean moisture pattern over the core Indian monsoon region $10^{\circ}-27.5^{\circ} \mathrm{N}, 70^{\circ}$ $105^{\circ} \mathrm{E}$ (blue rectangle in Fig. 5). These results thus lend further support to the critical role of summer mean lowertropospheric moisture on northward MJO propagation.

\section{Summary}

The MJO exhibits distinct seasonality in its propagation characteristics. While equatorial eastward propagation is dominant during boreal winter, pronounced poleward propagation prevails during summer over the Asian monsoon region. Using the moisture mode framework, several recent studies have highlighted the critical role of the mean moisture pattern for eastward propagation of the winter MJO (Jiang 2017; Gonzalez and Jiang 2017), and its seasonal variations in propagation characteristics (Adames et al. 2016). A moist entropy budget analysis is conducted in this study with a specific emphasis on northward propagation of the summer MJO in the IO.

Results suggest that the horizontal advection of the climatological ME distribution (approximately the lowlevel mean moisture) by MJO anomalous winds plays a dominant role in northward summer MJO propagation, the same process previously suggested as critical for the 
eastward propagation of the winter MJO. This study thus provides a unified interpretation under the moisture mode framework for both the equatorial eastward propagation of the winter $\mathrm{MJO}$ and also the northward propagation during summertime. The seasonal variations in the mean moisture pattern between winter and summer shapes the distinct seasonality of MJO propagation features. This notion is further supported by multimodel simulations that indicate that model skill in representing northward summer MJO propagation is tightly related to their fidelity in depicting the lower-tropospheric summer mean moisture pattern, similar to the winter MJO. Results presented here thus provide important guidance for model development in improving the representation of the MJO in weather and climate models.

Acknowledgments. We are grateful for the insightful comments from three anonymous reviewers. We acknowledge support by NOAA Climate Program Office under Awards NA15OAR4310098 (XJ), NA15OAR4310177 (XJ), NA17OAR4310261 (XJ), and NA15OAR4310099 (EM and AFA); NSF Climate and Large-Scale Dynamics Award AGS-1441916 (EM); and the Office of Naval Research Award N000141210580 (DW).

\section{REFERENCES}

Adames, Á. F., and J. M. Wallace, 2015: Three-dimensional structure and evolution of the moisture field in the MJO. J. Atmos Sci., 72, 3733-3754, https://doi.org/10.1175/JAS-D-15-0003.1.

— , and D. Kim, 2016: The MJO as a dispersive, convectively coupled moisture wave: Theory and observations. J. Atmos. Sci., 73, 913-941, https://doi.org/10.1175/JAS-D-15-0170.1.

_, J. M. Wallace, and J. M. Monteiro, 2016: Seasonality of the structure and propagation characteristics of the MJO. J. Atmos. Sci., 73, 3511-3526, https://doi.org/10.1175/JAS-D15-0232.1.

Ahn, M.-S., D. Kim, K. R. Sperber, I.-S. Kang, E. Maloney, D. Waliser, and H. Hendon, 2017: MJO simulation in CMIP5 climate models: MJO skill metrics and process-oriented diagnosis. Climate Dyn., 49, 4023-4045, https://doi.org/10.1007/ s00382-017-3558-4.

Andersen, J. A., and Z. Kuang, 2012: Moist static energy budget of MJO-like disturbances in the atmosphere of a zonally symmetric aquaplanet. J. Climate, 25, 2782-2804, https://doi.org/ 10.1175/JCLI-D-11-00168.1.

Arnold, N. P., and D. A. Randall, 2015: Global-scale convective aggregation: Implications for the Madden-Julian Oscillation. J. Adv. Model. Earth Syst., 7, 1499-1518, https://doi.org/ 10.1002/2015MS000498.

Benedict, J. J., E. D. Maloney, A. H. Sobel, and D. M. W. Frierson, 2014: Gross moist stability and MJO simulation skill in three full-physics GCMs. J. Atmos. Sci., 71, 3327-3349, https:// doi.org/10.1175/JAS-D-13-0240.1.

- M. S. Pritchard, and W. D. Collins, 2015: Sensitivity of MJO propagation to a robust positive Indian Ocean dipole event in the superparameterized CAM. J. Adv. Model. Earth Syst., 7, 1901-1917, https://doi.org/10.1002/2015MS000530.
Cai, Q., G. J. Zhang, and T. Zhou, 2013: Impacts of shallow convection on MJO simulation: A moist static energy and moisture budget analysis. J. Climate, 26, 2417-2431, https://doi.org/ 10.1175/JCLI-D-12-00127.1.

Chikira, M., 2014: Eastward-propagating intraseasonal oscillation represented by Chikira-Sugiyama cumulus parameterization. Part II: Understanding moisture variation under weak temperature gradient balance. J. Atmos. Sci., 71, 615-639, https:// doi.org/10.1175/JAS-D-13-038.1.

Dee, D. P., and Coauthors, 2011: The ERA-Interim reanalysis: Configuration and performance of the data assimilation system. Quart. J. Roy. Meteor. Soc., 137, 553-597, https://doi.org/ 10.1002/qj.828.

Gonzalez, A. O., and X. Jiang, 2017: Winter mean lower tropospheric moisture over the Maritime Continent as a climate model diagnostic metric for the propagation of the MaddenJulian oscillation. Geophys. Res. Lett., 44, 2588-2596, https:// doi.org/10.1002/2016GL072430.

Hsu, H. H., and C. H. Weng, 2001: Northwestward propagation of the intraseasonal oscillation in the western North Pacific during the boreal summer: Structure and mechanism. J. Climate, 14, 3834-3850, https://doi.org/10.1175/1520-0442 (2001) $014<3834$ :NPOTIO $>2.0 . C O ; 2$.

Hsu, P. C., and T. Li, 2012: Role of the boundary layer moisture asymmetry in causing the eastward propagation of the Madden-Julian oscillation. J. Climate, 25, 4914-4931, https:// doi.org/10.1175/JCLI-D-11-00310.1.

Huffman, G. J., and Coauthors, 2007: The TRMM Multisatellite Precipitation Analysis (TMPA): Quasi-global, multiyear, combined-sensor precipitation estimates at fine scales. J. Hydrometeor., 8, 38-55, https://doi.org/10.1175/JHM560.1.

Jiang, X., 2017: Key processes for the eastward propagation of the Madden-Julian Oscillation based on multimodel simulations. J. Geophys. Res. Atmos., 122, 755-770, https://doi.org/10.1002/ 2016JD025955.

— and T. Li, 2005: Reinitiation of the boreal summer intraseasonal oscillation in the tropical Indian Ocean. J. Climate, 18, 3777-3795, https://doi.org/10.1175/JCLI3516.1.

- — , and B. Wang, 2004: Structures and mechanisms of the northward propagating boreal summer intraseasonal oscillation. J. Climate, 17, 1022-1039, https://doi.org/10.1175/15200442(2004)017<1022:SAMOTN > 2.0.CO;2.

_ , and Coauthors, 2011: Vertical diabatic heating structure of the MJO: Intercomparison between recent reanalyses and TRMM estimates. Mon. Wea. Rev., 139, 3208-3223, https:// doi.org/10.1175/2011MWR3636.1.

— , and Coauthors, 2015: Vertical structure and physical processes of the Madden-Julian oscillation: Exploring key model physics in climate simulations. J. Geophys. Res. Atmos., 120, 4718-4748, https://doi.org/10.1002/2014JD022375.

_ M. Zhao, E. D. Maloney, and D. E. Waliser, 2016: Convective moisture adjustment time scale as a key factor in regulating model amplitude of the Madden-Julian Oscillation. Geophys. Res. Lett., 43, 10 412-10 419, https://doi.org/10.1002/ 2016GL070898.

Kim, D., J.-S. Kug, and A. H. Sobel, 2014: Propagating versus nonpropagating Madden-Julian oscillation events. J. Climate, 27, 111-125, https://doi.org/10.1175/JCLI-D-13-00084.1.

- H. Kim, and M.-I. Lee, 2017: Why does the MJO detour the Maritime Continent during austral summer? Geophys. Res. Lett., 44, 2579-2587, https://doi.org/10.1002/2017GL072643.

Kim, H.-M., 2017: The impact of the mean moisture bias on the key physics of MJO propagation in the ECMWF reforecast. 
J. Geophys. Res. Atmos., 122, 7772-7784, https://doi.org/ 10.1002/2017JD027005.

Kiranmayi, L., and E. D. Maloney, 2011: Intraseasonal moist static energy budget in reanalysis data. J. Geophys. Res., 116, D21117, https://doi.org/10.1029/2011JD016031.

Klingaman, N. P., X. Jiang, P. K. Xavier, J. Petch, D. Waliser, and S. J. Woolnough, 2015: Vertical structure and physical processes of the Madden-Julian oscillation: Synthesis and summary. J. Geophys. Res. Atmos., 120, 4671-4689, https://doi.org/ 10.1002/2015JD023196.

Lau, K.-M., and P. H. Chan, 1986: Aspects of the 40-50 day oscillation during the northern summer as inferred from outgoing longwave radiation. Mon. Wea. Rev., 114, 1354-1367, https://doi.org/ 10.1175/1520-0493(1986)114<1354:AOTDOD > 2.0.CO;2.

L'Ecuyer, T. S., and G. McGarragh, 2010: A 10-year climatology of tropical radiative heating and its vertical structure from TRMM observations. J. Climate, 23, 519-541, https://doi.org/ 10.1175/2009JCLI3018.1

Li, T., 2014: Recent advance in understanding the dynamics of the Madden-Julian oscillation. J. Meteor. Res., 28, 1-33, https:// doi.org/10.1007/s13351-014-3087-6.

Madden, R. A., and F. E. Robitaille, 1970: A comparison of the equivalent potential temperature and the static energy. J. Atmos. Sci., 27, 327-329, https://doi.org/10.1175/1520-0469 (1970)027<0327:ACOTEP >2.0.CO;2.

—_, and P. R. Julian, 1994: Observations of the 40-50-day tropical oscillation: A review. Mon. Wea. Rev., 122, 814837, https://doi.org/10.1175/1520-0493(1994)122<0814: OOTDTO $>2.0 . \mathrm{CO} ; 2$.

Maloney, E. D., 2009: The moist static energy budget of a composite tropical intraseasonal oscillation in a climate model. $J$. Climate, 22, 711-729, https://doi.org/10.1175/2008JCLI2542.1. , and D. L. Hartmann, 1998: Frictional moisture convergence in a composite life cycle of the Madden-Julian Oscillation. J. Climate, 11, 2387-2403, https://doi.org/10.1175/ 1520-0442(1998)011<2387:FMCIAC $>2.0$. CO 2 .

_ , and A. H. Sobel, 2004: Surface fluxes and ocean coupling in the tropical intraseasonal oscillation. J. Climate, 17, 43684386, https://doi.org/10.1175/JCLI-3212.1.

Mapes, B. E., and J. T. Bacmeister, 2012: Diagnosis of tropical biases and the MJO from patterns in the MERRA analysis tendency fields. J. Climate, 25, 6202-6214, https://doi.org/ 10.1175/JCLI-D-11-00424.1.

Neena, J. M., J. Y. Lee, D. Waliser, B. Wang, and X. Jiang, 2014: Predictability of the Madden-Julian Oscillation in the Intraseasonal Variability Hindcast Experiment (ISVHE). J. Climate, 27, 4531-4543, https://doi.org/10.1175/JCLI-D-13-00624.1.

_ D. Daliser, and X. Jiang, 2017: Model performance metrics and process diagnostics for boreal summer intraseasonal variability. Climate Dyn., 48, 1661-1683, https://doi.org/10.1007/ s00382-016-3166-8.

Petch, J., D. Waliser, X. Jiang, P. Xavier, and S. Woolnough, 2011: A global model intercomparison of the physical processes associated with the Madden-Julian Oscillation. GEWEX News, Vol. 21, No. 3, International GEWEX Project Office, Silver Spring, MD, 3-5.

Prasanna, V., and H. Annamalai, 2012: Moist dynamics of extended monsoon breaks over South Asia. J. Climate, 25, 38103831, https://doi.org/10.1175/JCLI-D-11-00459.1.

Pritchard, M. S., and C. S. Bretherton, 2014: Causal evidence that rotational moisture advection is critical to the superparameterized Madden-Julian Oscillation. J. Atmos. Sci., 71, 800-815, https://doi.org/10.1175/JAS-D-13-0119.1.
Raymond, D. J., 2001: A new model of the Madden-Julian oscillation. J. Atmos. Sci., 58, 2807-2819, https://doi.org/10.1175/ 1520-0469(2001)058<2807:ANMOTM>2.0.CO;2.

- 2013: Sources and sinks of entropy in the atmosphere. J. Adv. Model. Earth Syst., 5, 755-763, https://doi.org/10.1002/ jame.20050.

— , and Ž. Fuchs, 2009: Moisture modes and the Madden-Julian Oscillation. J. Climate, 22, 3031-3046, https://doi.org/10.1175/ 2008JCLI2739.1.

- S. Sessions, A. Sobel, and Z. Fuchs, 2009: The mechanics of gross moist stability. J. Adv. Model. Earth Syst., 1 (9), https:// doi.org/10.3894/james.2009.1.9.

Salby, M. L., R. R. Garcia, and H. H. Hendon, 1994: Planetaryscale circulations in the presence of climatological and waveinduced heating. J. Atmos. Sci., 51, 2344-2367, https://doi.org/ 10.1175/1520-0469(1994)051<2344:PSCITP>2.0.CO;2.

Sobel, A., and E. Maloney, 2012: An idealized semi-empirical framework for modeling the Madden-Julian Oscillation. J. Atmos. Sci., 69, 1691-1705, https://doi.org/10.1175/JAS-D11-0118.1.

- and - 2013: Moisture modes and the eastward propagation of the MJO. J. Atmos. Sci., 70, 187-192, https://doi.org/ 10.1175/JAS-D-12-0189.1.

_ S. Wang, and D. Kim, 2014: Moist static energy budget of the MJO during DYNAMO. J. Atmos. Sci., 71, 4276-4291, https:// doi.org/10.1175/JAS-D-14-0052.1.

Waliser, D. E., 2006: Intraseasonal variability. The Asian Monsoon, B. Wang, Ed., Springer, 203-257.

Wang, B., 2012: Theories. Intraseasonal Variability in the Atmosphere-Ocean Climate System, 2nd ed. W. K. M. Lau and D. E. Waliser, Eds., Springer, 335-398.

_ , and T. M. Li, 1994: Convective interaction with boundarylayer dynamics in the development of a tropical intraseasonal system. J. Atmos. Sci., 51, 1386-1400, https://doi.org/10.1175/ 1520-0469(1994)051<1386:CIWBLD>2.0.CO; 2 .

_ R. Wu, and T. Li, 2003: Atmosphere-warm ocean interaction and its impacts on Asian-Australian monsoon variation. J. Climate, 16, 1195-1211, https://doi.org/10.1175/1520-0442 (2003)16<1195:AOIAII >2.0.CO;2.

Wang, L., T. Li, E. Maloney, and B. Wang, 2017: Fundamental causes of propagating and nonpropagating MJOs in MJOTF/ GASS models. J. Climate, 30, 3743-3769, https://doi.org/ 10.1175/JCLI-D-16-0765.1.

Wang, T., S. Wong, and E. J. Fetzer, 2015: Cloud regime evolution in the Indian monsoon intraseasonal oscillation: Connection to large-scale dynamical conditions and the atmospheric water budget. Geophys. Res. Lett., 42, 9465-9472, https://doi.org/ 10.1002/2015GL066353.

Wong, S., E. J. Fetzer, B. Tian, B. Lambrigtsen, and H. Ye, 2011: The apparent water vapor sinks and heat sources associated with the intraseasonal oscillation of the Indian summer monsoon. J. Climate, 24, 4466-4479, https://doi.org/10.1175/ 2011JCLI4076.1.

Yokoi, S., and A. H. Sobel, 2015: Intraseasonal variability and seasonal march of the moist static energy budget over the eastern Maritime Continent during CINDY2011/DYNAMO. J. Meteor. Soc. Japan, 93A, 81-100, https://doi.org/10.2151/jmsj.2015-041.

Yu, L., X. Jin, and R. A. Weller, 2008: Multidecade Global Flux Datasets from the Objectively Analyzed Air-sea Fluxes (OAFlux) Project: Latent and sensible heat fluxes, ocean evaporation, and related surface meteorological variables. Woods Hole Oceanographic Institution, Woods Hole, MA, OAFlux Project Tech. Rep. OA-2008-01, 64 pp. 